\title{
POSITIVISMO E DESIGN: percepções sobre a influência positivista nas leis da gestalt
}

\author{
Eduardo Evangelista \\ Universidade Federal de Santa Catarina - UFSC \\ edu_evangelista@hotmail.com \\ Marco Aurélio Soares dos Santos \\ Universidade Federal de Santa Catarina - UFSC \\ marcoaurelio@univali.br \\ Paulo Henrique Wolf \\ Universidade Federal de Santa Catarina - UFSC \\ paulo_wolf@terra.com.br \\ Valéria Casaroto Feijó \\ Universidade Federal de Santa Catarina - UFSC \\ valeriafeijo@gmail.com \\ Richard Perassi Luiz de Sousa \\ Universidade Federal de Santa Catarina - UFSC \\ richard.perassi@uol.com.br \\ Luiz Salomão Ribas Gomez \\ Universidade Federal de Santa Catarina - UFSC \\ salodesigner@gmail.com
}

\begin{abstract}
Resumo: Partindo-se do entendimento de que o Design possui fundamentos filosóficos, este artigo busca investigar a influência positivista nas Leis da Gestalt e como essa influência pode ser percebida. Ao final do século XIX, a Gestalt após realização de experimentos e observações propõe leis para a compreensão do cérebro humano, que tende desmembrar uma imagem e organizá-la de acordo com semelhança de forma, cor, textura, possibilitando a compreensão do significado proposto. Nesta mesma época surge o positivismo como o objetivo de estudar as coisas do mundo, propondo uma nova forma de reorganização do conhecimento científico e consequentemente de reorganização social. Desta forma, realizou-se uma pesquisa bibliográfica e exploratória, que buscou estabelecer uma relação entre as bases de positivismo de Auguste Comte e as bases da Gestalt.
\end{abstract}

Palavras-chave: Positivismo; Gestalt; Ciência; Percepção; Leis. 


\begin{abstract}
Based on the understanding that the Design has philosophical foundations, this paper investigates the influence of Gestalt Laws in positivist and how this influence can be seen. At the end of the nineteenth century, the Gestalt after performing experiments and observation proposes laws to the understanding of the human brain, which tends dismember a picture and organize it according to similarity of form, color, texture, enabling an understanding of the intended meaning. At this same time positivism arises as to study the things of the world, proposing a new form of reorganization of scientific knowledge and consequently of social reorganization. Thus, we performed a literature search and exploratory, which sought to establish a relationship between the bases of positivism of Auguste Comte and the foundations of Gestalt.
\end{abstract}

Keywords: Positivism; Gestalt; Science; Perception; Laws

\title{
1. INTRODUÇÃO
}

O Positivismo foi uma importante doutrina filosófica que encontra-se na base do desenvolvimento da ciência moderna. A partir dos princípios filosóficos que buscavam uma forma de entender o mundo, distanciando-se da metafísica e aproximando-se das ciências empíricas, o positivismo tinha como principal foco a observação e a experimentação. O principal nome responsável pela difusão das ideias positivistas foi Auguste Comte.

A Gestalt foi a ciência que buscou estudar a percepção visual a partir a teoria da forma, e depois disso foi usada como embasamento para leitura de sistemas visuais. Hoje em dia esses sistemas visuais são múltiplos e tratam do design industrial, design gráfico, arquitetura, publicidade, moda, configurações ambientais, artes plásticas, fotografia, comunicação digital, entre outros.

Assim, o presente artigo busca estabelecer uma relação entre o positivismo de Auguste Comte e as Leis da Gestalt, com o objetivo de investigar se existe uma influência da filosofia positivista nas leis da Gestalt e de que maneira ela pode ser percebida. Trata-se de uma investigação, que parte do questionamento de que a existência de um método, ou de que a criação de leis, estaria diretamente ligada a filosofia positivista, entretanto, busca-se, além disso, verificar se existem outras características que podem ser consideradas como influência e que podem ser relacionadas entre as duas questões analisadas.

Para isso, buscou-se realizar uma pesquisa bibliográfica e exploratória, com análise de dados qualitativa. A pesquisa bibliográfica é necessária em qualquer área, pois visa justificar os objetivos e contribuir para melhor argumentação da pesquisa. Ela abrange toda a bibliografia já tornada pública em relação ao tema de estudo. Segundo Gil (1999), a pesquisa exploratória é desenvolvida no sentido de proporcionar uma visão geral acerca de determinado fato. É realizada quando o tema escolhido é pouco explorado e consiste no aprofundamento de conceitos sobre determinado tema por trabalhar com a pesquisa bibliográfica. A análise de dados foi realizada de maneira qualitativa, descrevendo a relação estabelecida entre positivismo e as Leis da Gestalt. 


\section{POSITIVISMO DE AUGUSTE COMTE}

O positivismo foi uma das primeiras doutrinas filosóficas do século XIX. Suas raízes encontram-se no empirismo de David Hume, que procurava entender as coisas do mundo de maneira mais científica, afastando-se do que não era exato e comprovável. Desta maneira, apenas o mundo dos valores e dos fatos seria reconhecido.

Os positivistas são os defensores das ciências empíricas e de seus procedimentos de observação e experimentação e desprezam as filosofias tradicionais por acreditarem que só a observação e a experiência podem trazer dados para serem trabalhados. Eles constatam a multiplicidade, diversidade e, às vezes, o caráter contraditório mesmo das teorias metafísicas. Para eles, apenas o império da positividade dos dados observacionais poderia nos auxiliar na difícil tarefa de pensar o certo e o errado (DUTRA, 2005).

Por outro lado, quem tornou o positivismo mais conhecido, e também acabou tornando-se quase que o sinônimo de suas próprias ideias, foi o pensador Auguste Comte, nascido em 19 de janeiro de 1978, na cidade de Montpellier na França. Com 16 anos, Comte entrou para a escola Politécnica de Paris, que foi considerada uma marca para a influência na formação de seus pensamentos, mesmo ele tendo permanecido apenas dois anos na escola.

A maior parte das ideias de Comte ganhou espaço durante o período chamado de Restauração (1815 a 1848), período extremamente conservador, quando os princípios liberais e democráticos da Revolução Industrial entraram em refluxo, sendo perseguidos pelos contrarrevolucionários (SCHILLING, 1998).

Em meio a revolução, enquanto alguns buscavam a volta do antigo regime, Auguste Comte entendeu que isso jamais seria possível e visualizou o surgimento de uma nova era: a Era Científica ou Positiva e decidiu dedicar sua vida para difundi-la.

A derrubada da velha ordem aristocrática e feudal, o declínio do poder da Igreja Católica, o avanço da Indústria e da técnica, o crescimento científico em geral, a fé otimista no progresso, o impasse entre o Liberalismo e o Absolutismo e entre a Democracia e uma busca de segurança e estabilidade num período pósrevolucionário formaram o pano de fundo para o comtismo (SCHILLING, 1998, p.132).

O núcleo da filosofia de Comte baseia-se no pressuposto de que a sociedade precisava ser reorganizada a partir de uma reforma intelectual do homem. Seria assim, necessário fornecer aos homens novas formas de pensar de acordo com o estado das ciências de seu tempo.

Comte fixou quatro objetivos principais para sua filosofia: pôr em evidência as lógicas do espírito humano; promover uma reforma geral na educação; promover o progresso nas diversas ciências e uma reorganização da sociedade em bases sólidas (DUTRA, 2005). Assim, o positivismo precisava estar baseado ao mesmo tempo em uma teoria da ciência e em uma teoria da sociedade, que por vez são apoiadas por uma teoria da história.

Pode-se perceber que o positivismo mesmo tentando colocar-se como uma doutrina contrária a metafísica, acaba se baseando em questões da história da humanidade que não precedem de observação ou experiência, quesitos tão defendidos por Comte. 
No primeiro objetivo proposto por Comte, encontra-se o desenvolvimento do espírito humano, que para Comte, passou sucessivamente por três estados consecutivos: a) o teológico ou fictício; b) metafísico ou abstrato e; c) positivo ou científico (DUTRA, 2005).

$\mathrm{Na}$ fase teológica, o que ganha destaque é a imaginação, sendo a observação reduzida a poucos casos. O homem compreende o mundo através dos Deus e espíritos, de forças sobrenaturais, e satisfaz-se em saber que pode recorrer a tais divindades para compreender ou justificar os fenômenos que acontecem em sua vida.

Esta fase é dividida em três períodos sucessivos: o fetichismo, no qual uma vida espiritual semelhante a do homem é atribuída aos seres naturais; o politeísmo, atribui a animação dos seres não a si mesmos mas a outros seres, invisíveis ou superiores e no monoteísmo, no qual o homem reúne todas as divindades em uma só (GIANNOTTI e LEMOS, 1983).

Após o estado teológico ou fictício, o espírito humano passaria pelo estado metafísico ou abstrato que é um estado intermediário, uma etapa de transição, no qual àquelas entidades do estado teológico são substituídas por forças abstratas. A única diferença entre estes dois estados é que os agentes naturais são substituídos por forças, e a imaginação dá lugar a argumentação. Porém, tanto a teologia quanto na metafísica, a "natureza íntima" das coisas continuava a ser buscada (DUTRA, 2005 e GIANNOTTI e LEMOS, 1983).

No estado positivo ou científico, segundo objetivo proposto por Comte, deixa-se de lado a cognição e a argumentação e passa-se a responder pela observação e à descrição dos fenômenos tais como eles se apresentam e como acontecem.

A pura imaginação perde, então, irrevogavelmente a sua antiga supremacia metal, e se subordina necessariamente à observação de maneira a construir um estado lógico plenamente normal sem cessar, entretanto, de exercer nas especulações positivas um trabalho tão capital como inesgotável, para criar ou aperfeiçoar os meios de ligação, quer definitiva, quer provisória. (COMTE, 1990, p. 15)

Assim, a visão do positivismo deixa de lado a causa dos fenômenos e tem como objetivo do conhecimento humano, nessa última fase, encontrar as relações invariáveis de sucessão e similaridade dos fenômenos, tornar-se pesquisa de suas leis.

Para o positivismo seria impossível reduzir os fenômenos a um só principio básico como explicação, por exemplo Deus. Comte acreditava que a partir da observação e da experiência seria possível perceber a interconexão entre determinados fenômenos.

A unidade que o conhecimento pode alcançar seria, assim, inteiramente subjetiva, radicando no fato de empregar-se um mesmo método, seja qual for o campo em questão: uma idêntica metodologia produz convergência e homogeneidade de teorias. Essa unidade do conhecimento não é apenas individual, mas também coletiva; isso faz da filosofia positiva o fundamento intelectual da fraternidade entre os homens, possibilitando a vida prática em comum (GIANNOTTI e LEMOS, 1983, p. 11).

Desta forma, a teoria e a prática estariam muito mais ligadas no estado positivo científico, já que o conhecimento a partir da observação, torna possível determinar futuros desenvolvimentos a partir da técnica, neste sentido, o positivismo estaria respondendo a indústria. 
As ciências positivas deveriam então, encontrar as leis que expressam as relações corretas entre os fenômenos, isto é, deveriam descobrir como tais fenômenos são dados nas observações.

É nas leis dos fenômenos que consiste realmente a ciência, à qual os fatos propriamente ditos, por mais exatos e numerosos que possam ser, nunca fornecem senão materiais indispensáveis. Ora considerando a destinação constante destas leis, pode-se dizer sem exagero algum que a verdadeira ciência, muito longe de ser formada por simples observações, tende sempre a prescindir, tanto quanto possível, da exploração direta [...] (COMTE, 1990, p. 18).

Segundo Comte, as ciências se organizam de uma forma natural e necessária em um sistema, de acordo com a maior ou menor simplicidade de seus objetivos. Para ele há seis ciências fundamentais, cuja complexidade estabelece a sequencia: A matemática é aquela que vem em primeiro lugar, seguida pela a astronomia, a física, química, biologia e sociologia (DUTRA, 2005).

A matemática seria entendida como a de menor complexidade pois possui um maior grau de generalidade e estuda a realidade mais simples e determinada. Já a sociologia é vista por Comte como "o fim essencial de toda a filosofia positiva" (GIANNOTTI e LEMOS, 1983, p. 12), e essa sociologia faria uma distinção entre a reforma das instituições, fundamentada na sociologia de Comte, que aconteceria a partir da condução da sociologia à política, fazendo assim da filosofia positivista um instrumento para a reforma intelectual do homem e consequentemente a reorganização da sociedade.

Numa palavra, a revolução fundamental que caracteriza a virilidade de nossa inteligência consiste essencialmente em substituir toda parte inacessível determinação das causas propriamente ditas pela simples busca das leis, isto é, das relações constantes que existem entre os fenômenos observados. (COMTE, 1990, p. 15)

Mas para isso acontecer, Comte acreditava que seria necessário uma "nova elite científico-industrial, capaz de formular os fundamentos positivos da sociedade e desenvolver as atividades técnicas correspondentes a cada uma das ciências" (GIANNOTTI e LEMOS, 1983, p. 12).

Além disso, pensadores como Carnap, Mach, Wittgestein entre outros, desenvolveram seus estudos baseados em semelhanças discutidas por Comte em sua doutrina filosófica, alguns com mais proximidade em relação as ideias, outros com um certo distanciamento, mas no geral, propondo uma maneira mais "lógica" de pensar a ciência, a partir de classificações, enunciados e leis.

\section{A EXPERIÊNCIA DA GESTALT: AS LEIS DA GESTALT}

A Gestalt - Escola de Psicologia Experimental - em seu sentido mais amplo, significa uma interação de partes em oposição à soma do "todo", é traduzido geralmente como forma ou configuração para o português.

Christian Von Ehrenfels (1859-1932), filósofo viensense do final do século XIX, é considerado o percursor da psicologia da Gestalt, ao elaborar a noção Gestaltquälitat ou "qualidade da forma". "Para ele, a 'qualidade' da experiência não pode ser reduzida a uma combinação 'quantitativa' de sensações" (Becker, 2011 p. 237). Mais tarde, por volta de 1910, o estudo teve seu início mais efetivo por meio de 
três nomes principais: Max Wertheimer (1880-1943), Wolfgang Köhler (1887-1967) e Kurt Koffka (1886-1941), da Universidade de Frankfurt (GOMES FILHO, 2008).

O movimento gestaltista atuou principalmente no campo da teoria da forma, com contribuição relevante aos estudos da percepção, permitindo esclarecer considerações relevantes acerca do sujeito.

Para a Gestalt, a mente humana diferencia no campo perceptivo, dois elementos dominantes, figura e fundo. Seus fundadores Koffa, Wertheimer e Köhler, afirmam que a percepção não se constitui apenas na soma de dados sensoriais recebidos passivamente pelo indivíduo. Ao contrário, ela é um processo ativo e sempre se refere a todos organizados sob uma forma ou estrutura conjunto, uma Gestalt, cujas as partes, se tomadas separadamente, não representam as mesmas características do todo.

A percepção está submetida a certas leis (lei do fechamento, da semelhança, etc.) que fazem uma figura emergir do fundo, o qual ao mesmo tempo a constitui e a circunscreve (Koffka, 1975 apud Lima; D'acri; Orgler, 2007). Desta forma, a figura é a percepção elaborada numa forma plena, pregnante, sobre o qual focaliza nossa atenção; e o fundo é o suporte "neutro" dessa figura, o espaço em volta, percebido de maneira vaga (Sekeff; Zampronha, 2004).

Vários experimentos e testes, feitos pelos psicólogos da Gestalt para analisar como as pessoas identificam as figuras, determinaram que o que acontece no cérebro não é idêntico ao que acontece na retina.

A excitação cerebral não se dá em pontos isolados, mas por extensão. Não existe, na percepção da forma, um processo posterior de associação das várias sensações. A primeira sensação já é de forma, já é global e unificada (KOFFA, WERTHEIMER, KÖHLER apud FILHO 2008).

A qualidade do todo não é apenas um elemento do conjunto, desta maneira, pode-se determinar as características das partes. A hipótese da Gestalt, para explicar as forças integradoras que se refere as relações psicofisiológicas - todo o processo consciente, que está estreitamente relacionada com as forças integradoras do processo fisiológico cerebral - é atribuir ao sistema nervoso central um dinamismo auto-regulador que, a procura de estabilidade, tende a organizá-las de acordo com semelhanças de forma, tamanho, cor, textura. Posteriormente reagrupadas em um conjunto gráfico que possibilita a compreensão do significado exposto (Koffa, Wetheimer, Köhler apud Filho 2008). As experiências unitárias (como se processam) definidas como gestalten, são estudadas e organizadas pela Gestalt, designando assim "leis de organização".

Para os teóricos desse sistema psicológico, nossa percepção está estruturada em caráter único, ou seja, uma alteração em partes do todo altera necessariamente o todo em si. Um dos principais objetivos da escola gestaltista era a elaboração de leis e princípios sobre a organização da percepção (BECKER, 2011).

Segundo Becker, as principais leis relativas a esse tema são:

1. Proximidade - elementos próximos no tempo e no espaço tendem a ser percebidos juntos.

2. Similaridade - elementos semelhantes tendem a ser percebidos como pertencentes à mesma estrutura.

3. Direção ou continuidade - diz a respeito à tendência a ver as figuras da maneira que a direção continue de modo fluido. 
4. Disposição objetiva - quando se vê um determinado tipo de organização, continua-se a vê-la mesmo quando os estímulos originais estão ausentes.

5. Destino comum - elementos deslocados, de maneira semelhante, de um grupo maior tendem a ser agrupados.

6. Pregnância - refere-se ao principio do "fechamento" (tende-se a "fechar" a forma de uma figura, mesmo que esta esteja incompleta) ou princípio do equilíbrio (as figuras são vistas de um modo tão "bom" quanto forem possíveis às condições do estímulo).

Para (Gomes Filho, 2008), metodologicamente podemos desenvolver um sistema de leitura visual da forma do objeto em duas etapas: a leitura visual do objeto e análise da estrutura perceptiva do objeto \& interpretação conclusiva. A primeira etapa, é sustentada na teoria das leis citadas anteriormente e consiste em:

Investigar e separar o objeto em suas partes ou unidades

principais;

Decompor estas unidades principais, em outras unidades de compositivas, até um nível satisfatório;

Identificar, analisar, interpretar, todas as unidades com cada uma da leis da Gestalt, descrevendo e caracterizando-as, como unidades separadas fisicamente, por meio de suas massas ou volumes, planos, ponto, linha, cores e atributos, tais como, brilho, textura, relevos positivos ou negativos.

Concluir a leitura visual, interpretando a organização formal do objeto, atribuindo um índice de avaliação para cada uma das leis, podendo ser o valor de 1 a 10.

A etapa seguinte requer repertório por parte do leitor, quanto ao entendimento das duas categorias conceituais acrescentadas, que complementam o sistema de leitura visual do objeto, através da leis da Gestalt. As categorias conceituais, de acordo com (Gomes Filho, 2008), são:

As fundamentais, consubstanciadas na harmonia, contraste e no equilíbrio visual buscam embasar a lei básica da pregnância da forma, cada qual subdividida em sub-categorias: harmononia (ordem, regularidade, desarmonia, desordem e irregularidade), equilíbrio (peso e direção, simetria, assimetria, desequilíbrio) e contraste (luz e tom, cor, vertical e horizontal, movimento, dinamismo, ritmo, passividade, proporção, proporção e escala, agudeza);

Técnicas Visuais Aplicadas, com a finalidade para leitura visual da forma, também fornecem embasamentos teóricos para procedimentos criativos na concepção e desenvolvimento de projetos de qualquer natureza, são elas: (clareza, simplicidade, minimidade, complexidade, propostas, profusão, coerência, incoerência, exageração, arredondamento, transparência física, transparência sensorial, opacidade, redundância, ambiguidade, espontaneidade, aleatoriedade, fragmentação, sutileza, diluição, distorção, profundidade, superficialidade, sequencialidade, sobreposição, ajuste óptico e ruído visual).

Nesta segunda, etapa o autor deverá procurar na leitura do objeto conceitos aproximados que definam igualmente diferentes categorias conceituais - e, por meio destas, realizar a sua análise.

Com a leitura detalhada, da organização visual do objeto, Gomes (2008), propõem a sistematização etapas complementares para realização da análise: a) analisar o objeto em um nível qualitativo; b) listar as categorias conceituais 
identificadas na configuração das unidades e/ou do objeto com um todo; d) escrever as diversas categorias conceituais, a fim de emitir juízo crítico e posicionamento pessoal em relação a interpretação formal do objeto analisado; e) interpretação conclusiva/ pregnância da forma: o leitor finaliza a analise, julgando se imagem do objeto reflete padrões de harmonia e equilíbrio no seu todo e/ou suas partes constitutivas ou se há divergência dos mesmos. Ao finalizar análise, o leitor deverá atribuir um índice de pregnância visual avaliando objeto em termos de qualidade formal.

A partir desses princípios a Gestalt propõe a aproximação entre a teoria e a técnica para então tornar-se algo aplicado e metodologicamente acessível com fácil compreensão. "Embora os gestaltistas queiram incluir todo o espectro da psicologia em sua perspectiva, privilegiaram o estudo da percepção" (BECKER, 2011 p. 241). Pois essa percepção, ou sensações, são atraídas por estes princípios e podem sob alguma medida ser mensuradas ou estimuladas.

Através de experimentos, os gestaltistas fundamentaram sua teoria estabelecendo o valor da experiência no fenômeno da percepção, uma vez compreendida a base dessa percepção é possível então buscar meios que sirvam de estímulos para uma potencialização dessa experiência perceptiva, algumas áreas de atuação, o design é uma delas, utilizam-se dessas leis e princípios gestaltistas agindo especificamente sobre estes aspectos.

\section{ANÁLISE: PERCEPÇÕES SOBRE A INFLUÊNCIA POSITIVA NAS LEIS DA GESTALT}

As percepções acerca da influência positivista na Gestalt, realizada a partir de uma revisão bibliográfica e exploratória sobre a filosofia positivista de Auguste Comte e a ciência da Gestalt e sua proposta de aplicação na forma de leis, é descrita abaixo.

A Gestalt surgiu, assim como o positivismo, no século XIX, como uma forma de encontrar sentido para as coisas no mundo, a partir dos estudos da percepção, e o positivismo com o objetivo de estudar as coisas do mundo e propor uma nova forma de reorganização do conhecimento científico e consequentemente de reorganização social. Neste sentido, primeiramente, pode-se ressaltar que apesar da Gestalt tratar de uma escola da psicologia experimental, há uma relação na definição dos seus métodos, entre observador e fato observado, sendo que assim como no positivismo, não podemos separar um do outro.

Os positivistas defendem as ciências empíricas e de seus procedimentos de observação e experimentação, os psicólogos da Gestalt buscam explicar através de experiências o fenômeno da percepção quanto à maneira como se ordenam ou se estruturam as formas psicologicamente percebidas.

Comte passou por três estados consecutivos para o desenvolvimento do espírito humano, entre eles o metafísico ou abstrato, aquelas entidades do estado teológico sendo substituídas por forças abstratas, finalizando no estado positivo ou científico, passando a responder pela observação e à descrição dos fenômenos tais como eles apresentam e como acontecem.

Desta mesma maneira, a escola da Gestalt distinguindo-se por sua radicalidade, foi responsável pela presença mais marcante de suas ideias nas reflexões filosóficas contemporâneas. Defendendo o abandono dos conceitos clássicos de sensação, associação e atenção, assim como o método introspeccionista - treino sistemático para que o observador seja capaz de perceber elementos prescritos pelo experimentador (GURWITSCH, 2002 apud CHOLFE, 2009).

A Gestalt tem a ver com o positivismo, também, no sentido de que ela em um primeiro momento, avalia as partes como a percepção do sentido, assim como Comte 
acreditava que o resultado da observação não era único, mas composto de partes que irão dar "forma" ao conhecimento, colocando que não pode-se reduzir a ciência a uma única explicação.

Para que a existência de algo seja comprovado é necessário que exista validação, tanto o positivismo como a gestalt buscaram maneiras de transformar 0 pensamento metafísico em leis que podem ser experimentadas e testadas. A experiência e a observação são realizadas a partir da sistematização, da utilização de um método que pode ser aplicado a diferentes objetos de estudo. Além disso, tanto o positivismo quanto a Gestalt possuem o entendimento de que o conhecimento gerado pela observação e experimentação não é baseado em um elemento único, mas que podem vários elementos gerar um entendimento do todo.

Assim com no positivismo a Gestalt enquanto ciência da percepção procurou se aproximar da técnica na medida em que suas leis foram utilizadas posteriormente como ferramentas para avaliação e leitura de sistemas visuais. O método, seria a forma de produzir convergência a unidade de teoria, podendo ela ser aplicada à técnica e assim responder a indústria, no caso da Gestalt e do contexto do presente artigo especificamente, a indústria do Design.

O que pode-se concluir é que a Gestalt apresenta uma contribuição científica e também teórica de forma a propor um entendimento tanto da percepção como do mundo físico, a partir de suas leis. Percebe-se assim uma revisão dos fatos vigentes na teoria positivista. O positivismo coloca-se como uma filosofia antimetafisica, estudando apenas as coisas do mundo, porém acaba se contradizendo quando utiliza coisas da história da humanidade que estão baseadas em metafísica, da mesma forma a Gestalt, apresenta características positivistas e ao mesmo tempo ela nega um pouco isso na medida em que ela descobre que o todo é maior do que as partes.

Para o design, a Gestalt é um excelente fator explicativo no processo de significação, identificação, criação e finalização do produto, propondo tornar compreensível os aspectos presentes durante todo o processo de criação e desenvolvimento.

\section{CONCLUSÃO}

Os gestaltistas ao mesmo tempo em que defendem a dependência da ciência ao "mundo fenomenal", determinam de forma igualitária que esta mesma deve preencher as lacunas deste mundo. A Gestalt ocupando o papel de princípio explicativo comum a todas as áreas do conhecimento contribui para um retorno da ciência para vida, como exigido por Koffka. Pode-se afirmar que os princípios gestaltistas, na medida em que defende uma ciência unitária, assemelham-se aos ideais do positivismo (TOCCAFONDI 2002, apud CHOLFE 2009).

A tecnologia é a aplicação da ciência nos processo de produção. Assim, o Design encontra-se no campo da tecnologia e as Leis da Gestalt são um elemento cientifico que está aplicado nesse processo tecnológico. Desta forma, é fundamental o estudo do ser humano, seus pensamentos, sentimentos reações, determinados pela sociedade que vive, e não por herança biológica.

Acreditamos que a tarefa do designer, do artista ou de qualquer outro profissional é a de conceber e desenvolver objetos que satisfaçam as necessidades de adequada estrutura formal, obviamente, respeitando-se os padrões culturais, estilos ou partidos formais relativos e intrínsecos aos diversificados objetos concebidos, desenvolvidos e construídos pelo homem. Pensamos que esse objetivo possa ser 
alcançado, tendo os estudos e experiências realizadas pela Gestalt no campo da percepção visual de forma. (GOMES FILHO 2008, p.17)

Hoje na perspectiva da tecnologia do Design, e por ser tecnologia implica no processo de aplicação da ciência na produção de projetos, o papel da gestalt é um papel relevante e ela tem sua base científica influenciada pelo positivismo, como podese constatar a partir do resultado da pesquisa bibliográfica e exploratória.

Entretanto, à medida que se percebe a influência do positivismo na Gestalt, percebe-se que ela evolui para a Gestalt terapia, que ela se molda e se transforma em um novo estudo e aprimora o estudo das Leis da Gestalt, e das questões fenomenológicas, que seriam importantes para novos estudos.

\section{REFERÊNCIAS}

BECKER, Letícia. Psicologia para concursos e graduação (recurso eletrônico): Teoria e questões. Rio de Janeiro: Elsevier, 2011.

CHOLFE, Jonas Fornitano. As implicações filosóficas da teoria da Gestalt. 2009. 193 f. Pós-graduação (Mestrado) - Curso de Filosofia, Universidade Federal de São Carlos, São Carlos, 2009.

COMTE, Auguste. Discurso sobre o espírito positivo. São Paulo: Martins Fontes, 1990

D'ACRI, Gladys; LIMA, Patrícia; ORGLER, Sheila.Dicionário de Gestalt-Terapia: Gestaltês. São Paulo: Summus, 2007.

DUTRA, Luiz Henrique de Araújo. Oposições filosóficas - A epistemologia e suas polêmicas. Florianópolis: Editora UFSC, 2005.

GIANNOTI, José Arthur (org.). Curso de filosofia positiva; Discurso preliminar sobre o conjunto do positivismo; Catecismo positivista/Auguste Comte. 2. ed. São Paulo: Abril Cultural, 1983.

GIL, Antonio Carlos. Métodos e técnicas de pesquisa social. 5. ed. São Paulo: Atlas, 1999.

GOMES FILHO, João. Gestalt do objeto: sistema de leitura visual da forma. 8.ed. São Paulo: Escrituras Editora, 2008.

SCHILLING, Voltaire. As grandes correntes do pensamento: da Grécia Antiga ao Neoliberalismo. 2.ed. Porto Alegre: Editora AGE LTDA, 1998.

SEKEFF, Maria de Lourdes; ZAMPRONHA, Edson S.; ORGLER, Sheila. Arte e cultura III: Estudos transdiciplinares. São Paulo: Fapesp, 2004. 